\title{
Planejamento de equipamentos urbanos comunitários de educação: algumas reflexões
}

\author{
The planning of urban community \\ education facilities: some reflections
}

Fernando Henrique Neves

\begin{abstract}
Resumo
Os equipamentos urbanos comunitários têm um grande potencial de ordenamento urbano. Através deles é possível criar ambientes urbanos de maior qualidade socioespacial e uma coerente distribuição espacial. Para isso, as diferentes maneiras de planejamento para implantação desses equipamentos necessitam ser compreendidas, tanto em seus aspectos qualitativos como técnicos. Esse artigo, por meio de literatura técnica e científica, explora diferentes critérios que podem ser utilizados para implantação de equipamentos urbanos comunitários de educação. São abordadas características do entorno, dimensionamento da capacidade, raio de influência, acessibilidade, circulação e a relação desses equipamentos com a sustentabilidade urbana. 0 artigo conclui ser fundamental o planejamento criterioso de equipamentos urbanos comunitários visando um melhor desenvolvimento do meio urbano e facilitar a gestão pública.
\end{abstract}

Palavras-chave: equipamentos urbanos comunitários; planejamento urbano; critérios de planejamento; implantação de escolas; meio ambiente urbano.

\begin{abstract}
Urban Community Facilities have a huge potential for urban development. With them, it is possible to create urban environments with higher sociospatial quality and a coherent spatial distribution. For this reason, the different ways of planning the implementation of Urban Community Facilities need to be understood, both in their qualitative and technical aspects. This article, through a review of technical and scientific literature, explores different criteria that can be used in the implementation of Urban Community Education Facilities. It approaches characteristics of the surroundings, capacity measurement, sphere of influence, accessibility, circulation and the relationship between these facilities and urban sustainability. The article concludes that the careful planning of Urban Community Facilities is essential to ensure a better development of the urban environment and to facilitate public management.
\end{abstract}

Keywords: urban community facilities; urban planning; criteria for planning; implementation of schools; urban environment. 


\section{Introdução}

0 planejamento de equipamentos urbanos comunitários normalmente é atribuído ao poder público e, em geral, com a finalidade de proporcionar o bem-estar à população, o ordenamento do território e aumentar a competitividade regional. No Brasil, a realidade do planejamento dos equipamentos urbanos aponta uma falta de critérios na implantação e locação desses equipamentos. Durante muitos anos, somente as partes das cidades brasileiras que atraíam a atenção dos planejadores foram beneficiadas pelos serviços públicos e tiveram uma participação desproporcional dos orçamentos locais (Brasil, 2010).

A fim de evitar essa desproporção de recursos destinados aos serviços públicos nos diferentes locais da cidade e tornar a implantação de equipamentos urbanos comunitários mais eficiente em termos de cobertura da população e valorização do espaço urbano, faz-se necessário um planejamento criterioso na implantação desses equipamentos. Nesse sentido, é fundamental a avaliação da complexidade do ambiente urbano, explorando, além do caráter técnico da infraestrutura urbana, suas possiblidades de interações sociais.

\section{Planejamento de equipamentos urbanos comunitários}

As possiblidades de interações sociais dos equipamentos urbanos são, de fato, fundamentais para qualificar bairros ou regiões das cidades. Para Moraes et al. (2008), os equipamentos urbanos comunitários são os componentes físicos básicos de infraestrutura urbana de uma cidade ou bairro, sendo a existência desses um fator determinante de bem-estar social e de apoio ao desenvolvimento econômico, além da potencialidade de ordenação territorial e de estruturação dos aglomerados humanos. Secchi (2003 apud Schafer, 2012) argumenta que "os espaços de uso público são entendidos como lugar de experiência social, no qual os equipamentos comunitários funcionam como locais de socialização". Contudo, a realidade do planejamento de equipamentos no Brasil, no geral, leva em consideração apenas características técnicas definidas em legislação sem, contudo, explorar aspectos qualitativos dos equipamentos urbanos comunitários.

A lei federal n. 6.766, de 1979, que dispõe sobre o parcelamento do solo urbano, traz a seguinte definição para equipamentos urbanos comunitários: "Consideram-se comunitários os equipamentos públicos de educação, cultura, saúde, lazer e similares" (art. $4^{\circ}$ parág. $2^{\circ}$ ). Complementando essa definição, a NBR 9284 conceitua-os como:

Todos os bens públicos ou privados, de utilidade pública, destinados à prestação de serviços necessários ao funcionamento da cidade, implantados mediante autorização do poder público em espaços públicos ou privados. (NBR 9284, 1986, p. 1)

A NBR 9284, além de definir os equipamentos urbanos comunitários, classifica-os em: circulação e transporte, cultura e religião, esporte e lazer, infraestrutura, sistema de comunicação, sistema de energia, sistema de iluminação pública, sistema de saneamento, 
segurança pública e proteção, abastecimento, administração pública, assistência social, educação e saúde.

Com relação ao planejamento para alocação de equipamentos urbanos comunitários, a lei federal n. 6.766, de 1979, discorre sobre áreas a serem reservadas para a implantação de equipamentos urbanos comunitários. De acordo com a referida lei, os equipamentos seriam computados nos 35\% de área pública a ser destinada quando elaborado o projeto de loteamento de uma gleba. No entanto, a lei n. 9.785/99 diz que as áreas destinadas aos equipamentos urbanos deverão ser "proporcionais à densidade de ocupação prevista pelo plano diretor ou aprovada por lei municipal para a zona em que se situem". Portanto, na ausência de definições para o planejamento de equipamentos urbanos comunitários, tais instruções técnicas deveriam estar contidas no plano diretor de cada município. No entanto, em muitos planos diretores municipais nota-se que não há normas urbanísticas concretas para implantação de equipamentos urbanos comunitários. Tratam apenas de forma superficial conceituando-os apenas, sem, contudo, expor critérios quanto ao seu dimensionamento e localização (Dreux, 2004).

Assim, o que se observa na prática é que os planos diretores muitas vezes são modelos de outros planos diretores de outras cidades e pouco definem com relação à realidade local para implantação de equipamentos urbanos comunitários (Dreux, 2004). Essa abordagem proporciona uma falta de compreensão da realidade local, pelo poder público municipal, para responder às demandas por infraestrutura, serviços e equipamentos públicos. Essas demandas são influenciadas principalmente pelo padrão de ocupação e desenho específico de determinados aglomerados urbanos, tanto na sua configuração técnica quanto no custo de implementação e manutenção (Lima, 2004).

Nessa perspectiva, diversos estudos técnicos e científicos (Batista et al., 2011; Colaço, 2011; Dreux, 2004; Dudzinska, 2009; Lima, 2003; Moreira et al., 2007; Mondo, 2012; Moraes et al., 2008; Marique et al., 2013; Perehouskei et al., 2007; Schafer, 2012) reconhecem a importância dos equipamentos urbanos comunitários e enfatizam a necessidade de uma compreensão no processo de planejamento desses equipamentos e suas relações sociais e físicas com o ambiente construído que os circunda, os quais serão explorados a seguir.

\section{Delimitação da pesquisa}

0 presente artigo abordará, especificamente, os equipamentos urbanos de educação, no entanto, as considerações aqui levantadas servem como subsídio para o estudo de planejamento de outros tipos de equipamentos, como equipamentos de saúde, lazer, segurança, entre outros.

Os equipamentos urbanos de educação essenciais para as cidades dividem-se no Brasil, principalmente, em instituições de atendimento infantil, escolas de ensino fundamental e médio. Há também escolas técnicas ou profissionalizantes e escolas especiais para portadores especiais. Muitas escolas, ainda, são divididas por nível de ensino, em função das necessidades de alunos de idades específicas (Kowaltowski, 2011). 
Através da revisão bibliográfica de artigos científicos e literatura técnica, a presente pesquisa identificou as seguintes considerações a serem feitas para implantação de equipamentos urbanos de educação: dimensionamento da área do terreno, do porte da edificação e dos raios de abrangência; potencial de criação de espaços urbanos mais sustentáveis; necessidade de articular-se com entorno; necessidade de planejamento da circulação. Tais considerações serão detalhadas na sequência.

\section{Dimensionamento e raios de abrangência de equipamentos urbanos comunitários de educação}

Dentre os autores que tratam de metodologias de determinação da capacidade dos raios de abrangência e acessibilidade dos equipamentos comunitários destacam-se Guimarães (2004), Gouvêa (2003), Ferrari (1977), Santos (1988), os quais discorrem que o dimensionamento de tais serviços deve ser calculado em função do índice de metro quadrado $\left(\mathrm{m}^{2}\right)$ de construção, do número de usuário/habitante do entorno, da distância a ser percorrida a pé e facilidade de deslocamento por transporte coletivo (Batista et al., 2011).

Santos (1988) descreve que a distribuição de equipamentos urbanos se difere de acordo com a escala do território urbano. 0 autor cita três escalas urbanas para a distribuição de equipamentos: a vizinhança, o bairro e a cidade. Na escala da vizinhança são desejáveis os equipamentos de educação como creche, pré-escola, escola de $1^{\circ} \mathrm{grau}$. Escola de $2^{\circ} \mathrm{grau}$ são desejadas na escala do bairro ou cidade.

Gouvêa (2008) em seus estudos apresenta requisitos de dimensionamento dos equipamentos urbanos comunitários baseados no Instituto de Planejamento do Distrito Federal e em estudos desenvolvidos nas décadas de 1970, 1980 e 1990 no Governo de Distrito Federal.

Para os equipamentos de educação, Gouvêa (2008) utiliza no cálculo de dimensionamento a porcentagem da população de classe econômica baixa com idade indicada para cada nível de ensino. Dividindo essa porcentagem pelo número de turnos máximo e pelo número de usuários máximo que o equipamento consegue entender, pode-se estimar o número de unidades a serem instaladas para atendimento à população considerada no cálculo. Assim a fórmula fica da seguinte forma:

$\{$ (População da área considerada $\times$ \%da população de classe baixa com idade própria que utiliza o equipamento) $\div$ número de turnos $\} \div$ capacidade máxima do equipamento.

Guimarães (2004) estabelece um índice de $\mathrm{m}^{2}$ de construção escolar por população para dimensionamento de equipamentos de ensino fundamental e médio. Dessa forma, o dimensionamento de equipamentos de ensino fundamental e médio pode ser obtido através de um cálculo em função da porcentagem de população em idade estudantil de 7 a 17 anos e o índice de $\mathrm{m}^{2}$ por aluno. Esse índice de $\mathrm{m}^{2}$ por aluno, o autor obtém dos dados existentes do Centro Brasileiro de Construções Escolares MEC (Cebrace). 0 autor então adota um turno e aplica ainda no cálculo um coeficiente correspondente ao baixo aproveitamento encontrado em comunidades semelhantes. 
0 quadro abaixo sintetiza e permite comparar através de fácil visualização os critérios dos diversos autores:

Embora os autores citados apontem métodos para dimensionamento de alguns equipamentos urbanos comunitários, nota-se, no Brasil, que ainda há uma carência de sistematização em forma de norma ou instrução técnica detalhada que regulamenta o planejamento urbano desses equipamentos.

Em Portugal, por exemplo, esta regulamentação é definida na "Norma para a programação de equipamentos coletivos" publicadas pela Direção Geral do Ordenamento do Território e Desenvolvimento Urbano, DGOTDU (Colaço, 2011). No México, os critérios para implantação de equipamentos urbanos comunitários são definidos através do "Sistema Normativo de Equipamiento Urbano" desenvolvido pela Secretaria de Desarrolo Social (Sedesol). Guias para planejamento e implantação de equipamentos urbanos comunitários também podem ser encontrados em diversas cidades com elevado controle de planejamento urbano como Hong Kong no Japão e Abu Dhabi nos Emirados Árabes Unidos.

\section{Quadro 1 - Síntese dos critérios para dimensionamento de alguns equipamentos urbanos comunitários, conforme autores}

\begin{tabular}{|c|c|c|c|}
\hline & $\begin{array}{l}\text { Santos } \\
(1988)\end{array}$ & $\begin{array}{c}\text { Guimarães } \\
\text { (2004) }\end{array}$ & $\begin{array}{c}\text { Gouvêa } \\
(2008)\end{array}$ \\
\hline 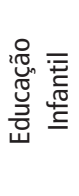 & $\begin{array}{l}\text { terreno com área de } 6 \mathrm{~m}^{2} \text { por criança } \\
\text { e edifício com } 4 \mathrm{~m}^{2} \text { por criança; as } \\
\text { turmas devem ser de no máximo } 20 \\
\text { alunos }\end{array}$ & & $\begin{array}{l}\text { área mín.do terreno: } 3.000,00 \mathrm{~m}^{2} ; \\
\text { raio de abrangência: } 300 \mathrm{~m} ; \mathrm{n}^{\circ} \text { de } \\
\text { alunos por sala de aula: } 15 \text { a } 25 ; \mathrm{n}^{\circ} \\
\text { de salas por equipamento: } 12 ; \\
\text { funcionamento em } 1 \text { turno }\end{array}$ \\
\hline 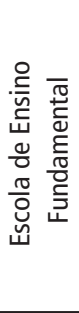 & $\begin{array}{l}\text { atender } 20 \% \text { da população servida; } \\
\text { terreno com } 6,4 \mathrm{~m}^{2} \text { por aluno (nunca } \\
\text { inferior a } 1.000 \mathrm{~m}^{2} \text { ); edificação } \\
\text { área de aprox. } 3,2 \mathrm{~m}^{2} \text { por aluno; } \\
\text { as turmas com capacidade de } 40 \\
\text { alunos; apresentar áreas livres para } \\
\text { esportes; apresentar áreas para } \\
\text { expansão }\end{array}$ & $\begin{array}{l}0,507 \mathrm{~m}^{2} \text { de área } \\
\text { construída por pop; } \\
\text { raio de abrangência: } \\
800 \text { metros }\end{array}$ & $\begin{array}{l}\text { área mín. do terreno: } 8.000,00 \mathrm{~m}^{2} ; \\
\text { raio de abrangência máx.: } \\
1.500 \text { metros; } \mathrm{n}^{\circ} \text { de alunos por } \\
\text { equipamento: } 1.050 ; \mathrm{n}^{\circ} \text { de salas por } \\
\text { equipamento: } 15 ; \\
\text { funcionamento em } 2 \text { turnos }\end{array}$ \\
\hline 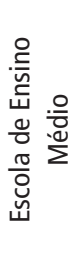 & $\begin{array}{l}\text { devem atender ao bairro ou quando } \\
\text { especializados a toda a cidade; } \\
\text { apresentar índices de terreno e } \\
\text { construção similar às escolas de } 1^{\circ} \\
\text { grau; salas de aula dimensionadas } \\
\text { para no máximo } 40 \text { alunos }\end{array}$ & $\begin{array}{l}0,182 \mathrm{~m}^{2} \text { de área } \\
\text { construída por pop; } \\
\text { raio de abrangência: } \\
1.600 \text { metros }\end{array}$ & $\begin{array}{l}\text { área mín. do terreno: } 11.000,00 \mathrm{~m}^{2} ; \\
\text { raio de abrangência máximo: } \\
3.000 \mathrm{~m} ; \mathrm{n}^{\circ} \text { de alunos por } \\
\text { equipamento: } 1.440 ; \mathrm{n}^{\circ} \text { de alunos } \\
\text { por sala de aula: } 40 \text { a } 45 ; \mathrm{n}^{\circ} \text { de } \\
\text { salas por equipamento: } 18 ; \\
\text { funcionamento em } 2 \text { turnos }\end{array}$ \\
\hline
\end{tabular}

Fonte: o autor (2014). 
É fundamental, no entanto, ao se dimensionar às áreas a serem ocupadas por equipamentos urbanos comunitários estabelecer índices de área de terreno e índices área construída sempre considerando a densidade demográfica. Nesse sentido, o raio de abrangência pode variar dependendo das diferentes densidades demográficas.

\section{Equipamentos urbanos e sustentabilidade}

A partir da década de 1980, houve um aumento de metodologias no campo da gestão ambiental, assim como nas leis que protegem o meio ambiente. Nesse contexto, houve uma crescente disseminação de termos como biocidades, construções sustentáveis, projetos ecológicos, entre outros que constituem uma tendência atual, buscando rever conceitos que priorizam a interação entre edificação, meio ambiente, cultura e a cidade como um todo.

Segundo Lima (2004), a base da sustentabilidade está fundamentada nas relações de trabalho, ou seja, relação homem-natureza, com suas implicações sociais, econômicas e políticas, possibilitando que o planejamento da infraestrutura urbana, serviços e equipamentos urbanos potencializem características mais sustentáveis no meio urbano.

Diante disso, ao tratar de sustentabilidade de bairros ou regiões é fundamental considerar o planejamento dos equipamentos urbanos.

A sustentabilidade urbana atingida por equipamentos urbanos comunitários acessíveis acontece à medida que dotam espaços urbanos de certa autonomia, minimizando deslocamentos e incentivando interações socioespaciais. A acessibilidade ao equipamento urbano corresponde ao grau de proximidade, em termos de localização, de que esse equipamento está de sua demanda ou usuário. Para isso devem ser analisados quais são os meios de deslocamento do usuário até esse equipamento, por exemplo: é acessível a pé, é acessível por transporte público, é acessível por ciclovias, é acessível por vias urbanas coletoras, etc.

O Guia de Sustentabilidade da Caixa Econômica Federal (2010) cita os equipamentos urbanos desejáveis no entorno de empreendimentos habitacionais. Um dos critérios de avaliação da qualidade de entorno para habitações mais sustentáveis, segundo o guia, diz respeito à existência e distância de equipamentos urbanos comunitários de saúde, lazer e educação. Segundo o guia, para inserção de empreendimento habitacional na malha urbana, dentre outros requisitos, deverá haver no mínimo "uma escola pública de ensino fundamental acessível por rota de pedestres de no máximo 1,5 km de extensão".

0 guia LEED (2009) para bairros sustentáveis tem como referência o conceito de unidade de vizinhança de Clarance Perry de 1929. Esse conceito parte da premissa que as cidades deveriam ser estruturadas em termos de pequenas unidades residenciais definidas em torno de uma escola primária, com população suficiente para justificar a respectiva existência. Nesse conceito, os equipamentos urbanos deveriam estar próximos às habitações, e essas não deveriam ser interrompidas por vias de trânsito de passagem, mas apenas tangenciadas, preservando a vida comunitária e dando segurança às crianças. 
Figura1 - Mapa de localização do empreendimento e entorno imediato para ambientes urbanos mais sustentáveis

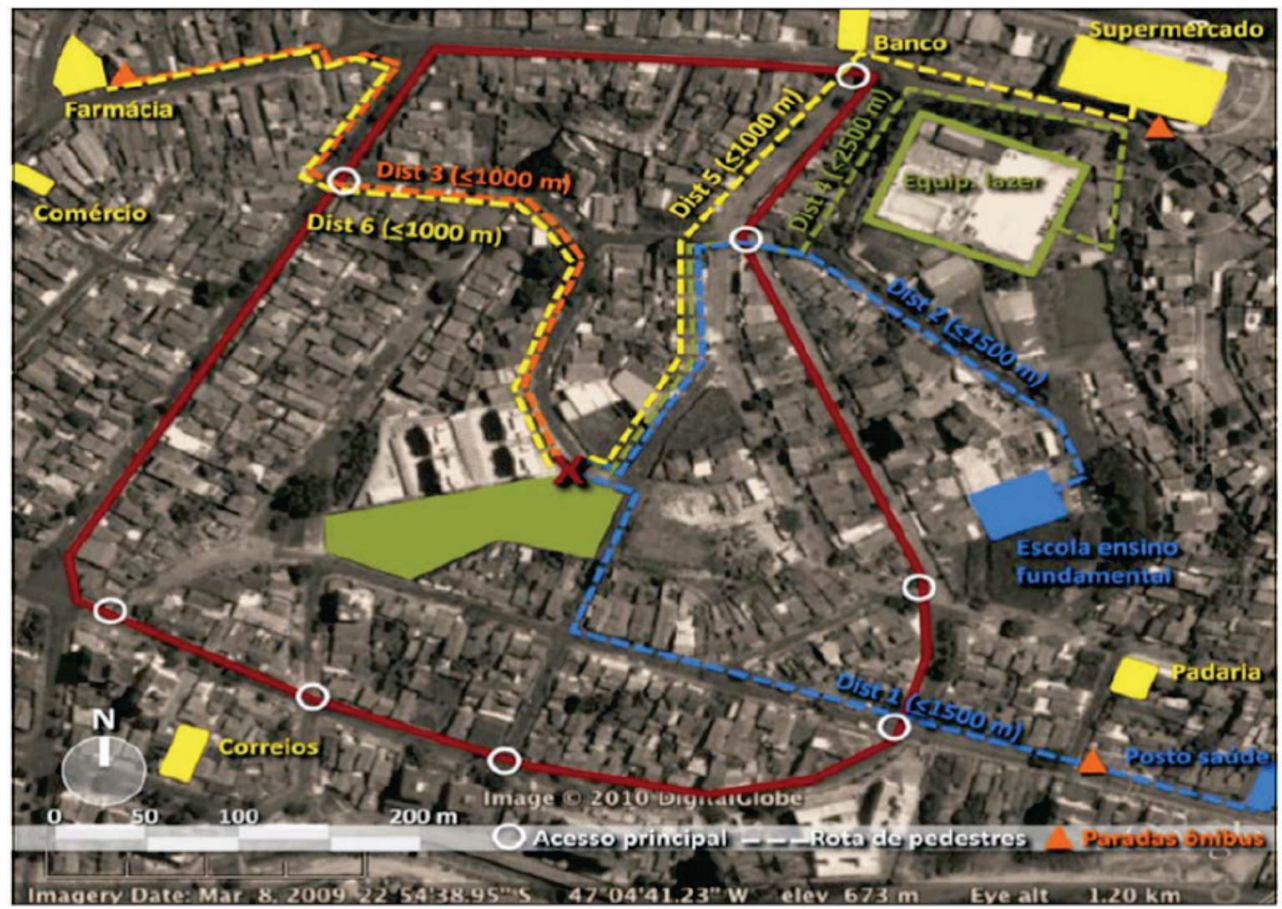

Fonte: Guia de Sustentabilidade da Caixa Econômica Federal (2010).

Dessa forma, o guia LEED (2009) para bairros sustentáveis dispõe de um capítulo exclusivo para a implantação de escolas nos bairros. 0 guia recomenda para um projeto de bairro sustentável que as escolas devam estar locadas de tal forma que pelo menos $50 \%$ das unidades de habitação estejam a uma distância de 1/2 milha caminhando até uma escola primária ou a uma distância de 1 milha de uma escola de nível médio. 0 deslocamento por bicicleta até algum estabelecimento de ensino, em um bairro exclusivamente residencial, deve ser de uma distância de 3 milhas percorrids por ciclovias. 0 guia também recomenda controle de tráfego próximo às escolas e calçadas e ciclovias bem estruturadas no seu entorno, compatibilizando-as com o tráfego de ônibus e áreas de embarque e desembarque.

Assim, a implantação de escolas no bairro, segundo o guia LEED (2990), estimula interação e engajamento da comunidade. Também promove a saúde dos alunos ao estimulá-los a se deslocar a pé ou por bicicleta.

Outros indicadores de sustentabilidade urbana como HQE2R, GEO Cidades: Indicadores Ambientais Urbanos e ZED também recomendam a necessidade de se considerar os equipamentos urbanos para garantir a qualidade socioambiental nos espaços urbanos (Camacho et al., 2011). 
Figura 2 - Proposta de unidade de vizinhança de Clarence Perry

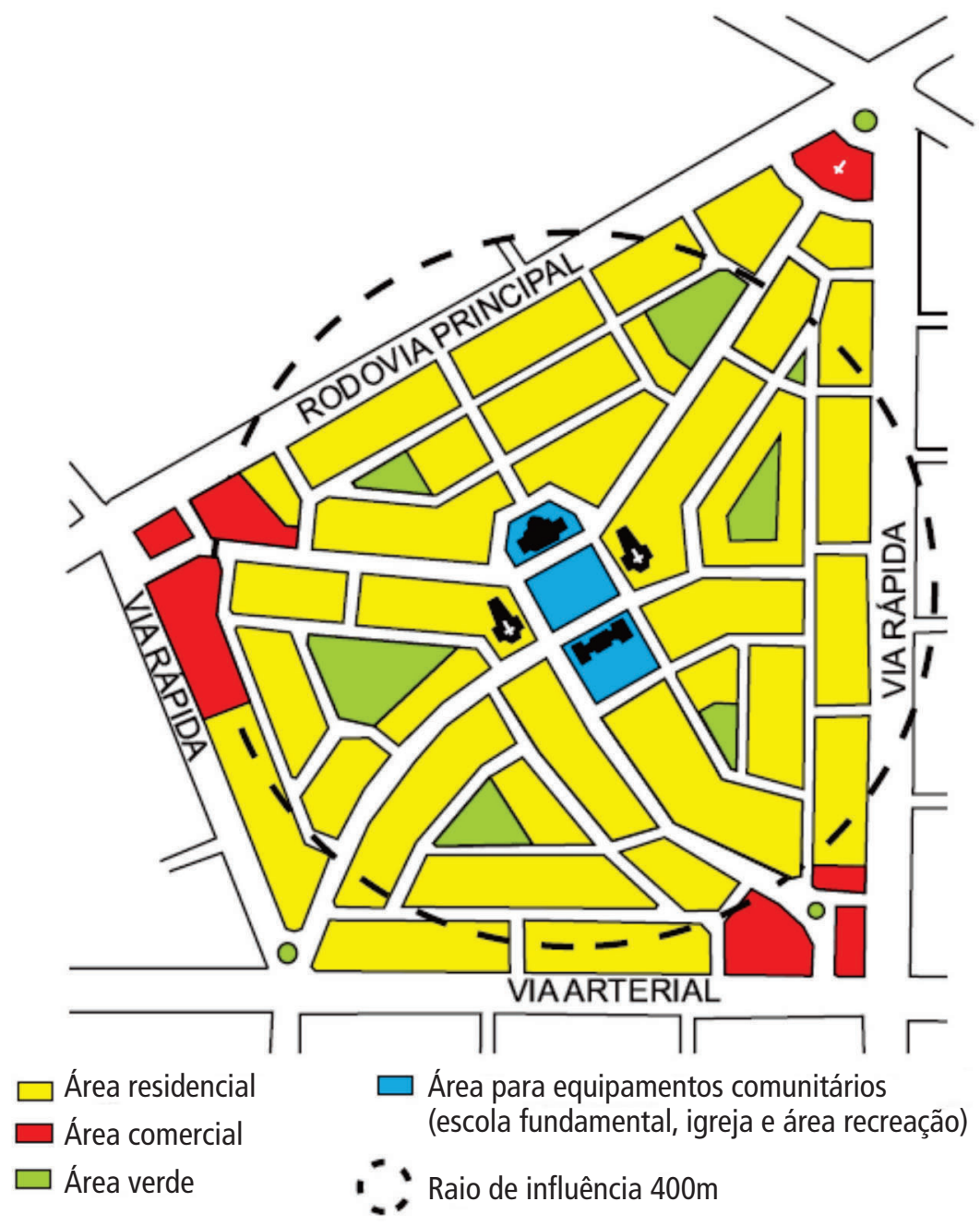

Fonte: Google Imagens, modificado pelo autor (2014). 


\section{Entorno e equipamentos urbanos}

Para Rio (1990), o ambiente que nos cerca sugere, facilita, inibe ou define comportamentos e ações, pressupondo, portanto, que a acessibilidade no entorno de equipamentos públicos também está relacionada com as características destes ambientes, no que tange aos aspectos físico-operacionais, tais como: uso do solo, configuração espacial, circulação viária e estacionamento, espaços livres, percursos de pedestres, atividades de apoio e mobiliário urbano.

Do mesmo modo, a relação do comportamento humano com o entorno de equipamentos de educação tem impactos diretos e indiretos na vizinhança que devem ser considerados durante a fase de planejamento de implantação destes equipamentos. Estudos de impacto de vizinhança têm sido cada vez mais exigidos por algumas prefeituras, nos quais são abordadas questões de tráfego, ruído, estacionamento, limpeza pública e estudos sobre a evolução no uso do solo da região onde será erigido um edifício de educação.

Com relação aos usos no entorno urbano, de fato, há equipamentos urbanos comunitários que se complementam ou que atraem novos tipos serviço. Gouvêa (2008) observa que para uma determinada comunidade analisada no Distrito Federal uma boa estratégia seria locar as creches próximas às escolas de ensino fundamental, visto que grande parte daquela comunidade tinha mais de um filho em diferentes idades escolares. A locação desses equipamentos próximos um do outro facilita, portanto, a logística de levar e buscar os filhos.

Figura 3 - Relação de vizinhança de equipamentos entre si
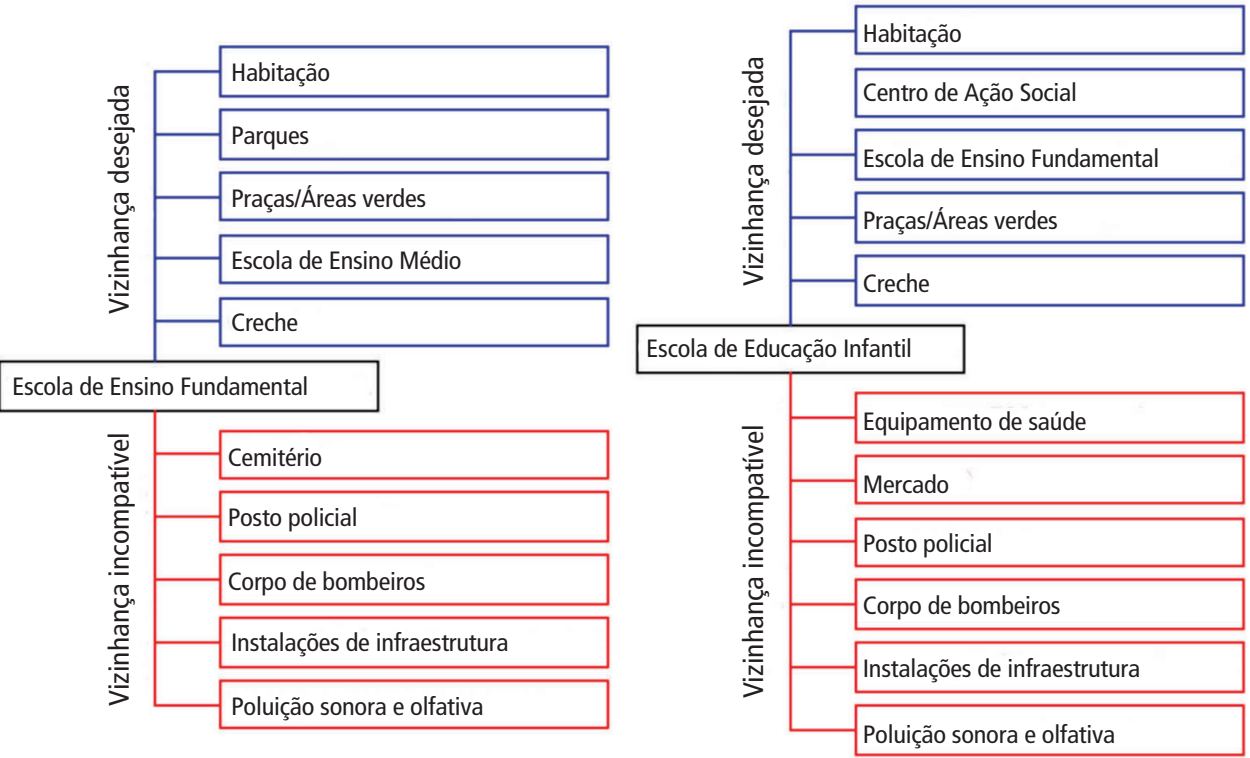

Fonte: 0 autor (2014), baseado em Santos (1988, p.162). 
Santos (1988) elenca os equipamentos que são desejáveis e indesejáveis na relação de vizinhança entre equipamentos e partir disso é possível esboçar o seguinte diagrama para os equipamentos de educação:

\section{Circulação e equipamentos urbanos}

Desconsiderar as condições do usuário para chegar aos equipamentos urbanos comunitários, ao implantar equipamentos de educação objetivando atendimento de uma demanda, pode tornar esses equipamentos inacessíveis ou pouco eficientes

Vasconcellos (2005) apresenta que 70\% a $80 \%$ dos deslocamentos das pessoas são em decorrência do trabalho e educação. Condizente com isso, alguns equipamentos de educação são considerados polos geradores de tráfego. Segundo Denatran (2001), os polos geradores de tráfego são empreendimentos de grande porte que atraem ou produzem grande número de viagens, causando reflexos negativos na circulação viária em seu entorno imediato e, em certos casos, prejudicando a acessibilidade de toda a região, além de agravar as condições de segurança de veículos e pedestres. Portanto, no planejamento de equipamentos urbanos comunitários de educação, a adequação da circulação no seu entorno também é de responsabilidade do poder público e cabe a esse destinar espaços para diferentes usuários, incluindo pedestres, ciclistas e condutores de veículos, com a finalidade de contribuir diretamente para o bom desempenho do trânsito e do bem-estar das comunidades (Denatran, 2001).
No Brasil, não existem ainda estudos sobre o número de acidentes próximo às escolas, sendo, no entanto, os conflitos de circulação no entorno das escolas de fato preocupante. Segundo Moreira et al. (2007), as características das crianças, seus modos de deslocamento, comportamento dos motoristas, localização inadequada das escolas em relação à hierarquia viária, características do sistema viário, sinalização, uso e ocupação do solo e a ausência de infraestrutura adequada para pedestres e ciclistas, que proporcione deslocamentos seguros e eficientes no percurso casa-escola, são os principais fatores que influenciam na causa de acidentes envolvendo alunos. Nesse sentido, as vias de circulação de veículos com tráfego intenso devem ser evitadas visando a segurança dos alunos. As vias devem ser bem sinalizadas, com sinalização vertical e horizontal. Há ainda, dependendo do porte da escola, municípios que exigem vias paralelas de desaceleração ou de embarque e desembarque, como forma de minimizar impacto de vizinhança. Essa medida objetiva minimizar transtorno com tráfego de veículos nos horários de entrada e saídas de aluno, por exemplo.

A rede de transporte público também deve estar compatibilizada com a implantação dos equipamentos urbanos comunitários de educação. Assim é sempre desejável ter pontos de ônibus no entorno desses equipamentos. De acordo com Campos Filho (2003), a distância confortável para se andar a pé até um equipamento urbano comunitário não deve ser superior a $800 \mathrm{~m}$.

Outro aspecto importante a se considerar com relação aos deslocamentos para escola é a característica saudável para a criança que essa atividade pode proporcionar. Gallimore et al. (2011) apontam em seus 
estudos que entre 1969 e 2001, nos Estados Unidos, o deslocamento para escola caminhando diminuiu de $40,7 \%$ para $12,9 \%$, tendo relação direta com o aumento de obesidade das crianças nesse mesmo período. 0 mesmo autor mostra que a caminhada para a escola foi associada com níveis mais saudáveis de atividade física medido em diversos estudos, concluindo que, para formação de passeios saudáveis para a escola, as comunidades devem superar três tipos de barreiras: barreiras de nível macroambiental (por exemplo: rotas indiretas, percursos longos, barreiras urbanas que desconectam ruas ou bairros); barreiras de nível microambiental (por exemplo: ausência de faixas de pedestres, semáforos); e barreiras percebidas (por exemplo: preocupação do pai do aluno com a segurança).
Outro ponto positivo que a escola acessível através da caminhada pode proporcionar é a contribuição para redução no consumo de energia. Marique et al. (2013) destacam a influência da forma urbana e localização de escolas nos deslocamentos e consumo de energia nas cidades. 0 autor conclui que a escola acessível através de caminhada também proporciona cidades mais eficientes do ponto de vista energético. Keirstead e Shah (2011) também têm estudos relacionando a forma urbana e consumo de energia. Os autores desenvolveram um modelo de informação que permite avaliar a energia mínima utilizada em determinadas formas urbanas em decorrência de deslocamentos de pessoas e transporte, exemplificando as escolas como equipamentos urbanos a serem considerados nesse sentido.

Figura 4 - Características de uma escola acessível através de caminhada

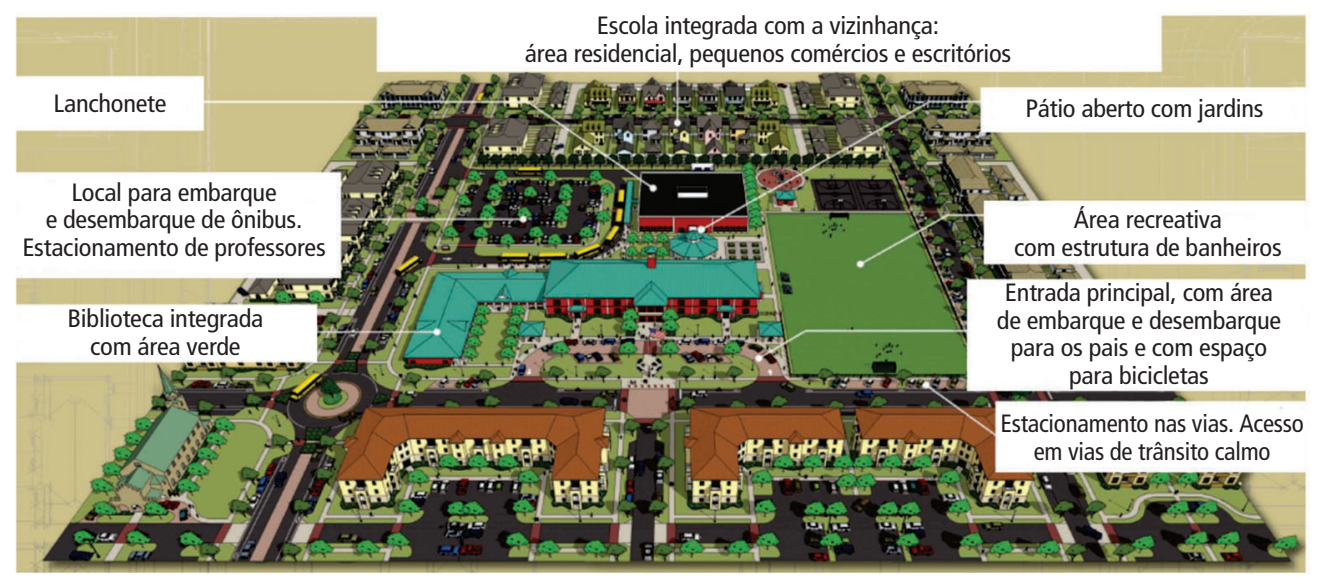

Fonte: Walkable and Livable Communities Institute (2010). Traduzido e reorganizado pelo autor. 


\section{Considerações finais}

A presente pesquisa, de caráter exploratório, mostra a importância da inserção de equipamentos urbanos comunitários no processo do planejamento urbano, sendo fundamental contextualizá-los na malha urbana buscando a compatibilização dos usos na cidade. Assim, através do planejamento criterioso é possível conceber a localização ótima de equipamentos urbanos e reservar áreas estratégicas para uma melhor qualidade socioespacial.

Ao tratar de sustentabilidade urbana, os equipamentos urbanos comunitários contribuem com o tema devido à capacidade desses equipamentos de instigarem relações sociais e contribuírem para a qualidade do espaço. Os equipamentos urbanos comunitários também podem proporcionar a redução de deslocamentos na cidade e, consequentemente, redução no consumo de energia, dotando um bairro ou região de certa autonomia.

A pesquisa ainda mostrou métodos que diversos autores utilizam para o dimensionamento de equipamentos urbanos comunitários.
Os métodos, de uma maneira geral, consideram índices de área de terrenos por habitante a serem reservadas para equipamentos urbanos comunitários e índices de área construída dos equipamentos por habitante.

Por fim, o presente artigo indicou algumas considerações no planejamento de equipamentos urbanos comunitários de educação como: integração e compatibilidade com a vizinhança; índices de terrenos a serem disponibilizados para equipamentos de acordo com a densidade demográfica pretendida para a região; relação com a sustentabilidade urbana; relação com vias de circulação e tráfego. Nesse sentido é pertinente o desenvolvimento de pesquisas futuras buscando gerar subsídios para complementação da atual legislação brasileira por meio de instruções técnicas ou norma que considerem detalhadamente tais critérios. Atualmente, o fato de caber aos planos diretores municipais a responsabilidade para estipular critérios com relação a isso possibilita a implantação de equipamentos urbanos de forma pouco sustentável, pouco acessível à população, mal locados e mal dimensionados.

\section{Fernando Henrique Neves}

Universidade Federal do Paraná, Programa de Pós-graduação em Engenharia de Construção Civil. Curitiba/PR, Brasil.

fernando.neves@ifpr.edu.br 


\section{Referências}

ASSOCIAÇÃO BRASILEIRA DE NORMAS TÉCNICAS (1986). NBR 9284: Equipamento Urbano: classificação. Rio de Janeiro.

BRASIL. Ministério das Cidades (2010). O Estatuto da Cidade Comentado. Disponível em: http://www. cidades.gov.br/. Acesso em: 13 maio 2014.

BRASIL. Presidência da República, Casa Civil, Subchefia para Assuntos Jurídicos (1979). Lei n. 6.766 de 1979. Disponível em: http://www.planalto.gov.br/ccivil_03/leis/I6766.htm. Acesso em: 27 out 2013.

BRASIL (1993). Lei n. 8.666, de 21 de junho de 1993. Disponível em: http://www.planalto.gov.br/ ccivil_03/leis/I8666cons.htm. Acesso em: 27 out 2013.

(1999). Lei n. 9.785 de 1999. Disponível em: http://www.planalto.gov.br/ccivil_03/leis/l9785. htm. Acesso em: 27 out 2013.

BATISTA, G.; ORTH, D. e BORTOLUZZI, S. (2011). Geoprocessamento para determinação de acessibilidade aos equipamentos educacionais como ferramenta de apoio aos Estudos de Impacto de Vizinhança: estudo de caso na Planície do Campeche - Florianópolis/SC - Brasil. In: XV SIMPÓSIO BRASILEIRO DE SENSORIAMENTO REMOTO - SBSR. Anais.

CAIXA ECONÔMICA FEDERAL (2010). Boas práticas para habitação mais sustentável. São Paulo, Páginas \& Letras.

CAMACHO, N.; ONGARO, D. e ZAMBRANO, L. (2011). Requisitos para avaliação de sustentabilidade de empreendimentos de interesse social. In: VI ENCONTRO NACIONAL E IV ENCONTRO LATINOAMERICANO SOBRE EDIFICAÇÕES E COMUNIDADES SUSTENTÁVEIS - Vitória/ES. Anais.

CAMPOS FILHO, C. M. (2003). Reinvente seu bairro: caminhos para você participar do planejamento de sua cidade. São Paulo, Editora 34.

COLAÇO, P. M. L. M. (2011). Critérios para o planeamento de equipamentos de saúde-Análise de caso de estudo no contexto urbano da AML. Dissertação de mestrado. Lisboa, Universidade de Lisboa.

DENATRAN. (2011). Manual de procedimentos para o tratamento de polos geradores de tráfego. Brasília, Denatran/FGV.

DREUX, V. (2004). Uma avaliação da legislação urbanística na provisão de equipamentos urbanos, serviços e áreas de lazer em conjuntos habitacionais. Dissertação de Mestrado. Porto Alegre, Universidade Federal do Rio Grande do Sul.

DUDZINSKA, E. (2009). Subsídios para localização dos equipamentos de ensino público na cidade de Palamas - TO. Dissertação de Mestrado. Brasília, Universidade de Brasília.

FERRARI, C. (1977). Curso de planejamento municipal integrado: urbanismo. São Paulo, Pioneira.

GALLIMORE, J.; BROWN, B. e WERNER, C. (2011). Walking routes to school in new urban and suburban neighborhoods: An environmental walkability analysis of blocks and routes. Journal of Environmental Psychology, n. 31, pp. 184-191.

GOUVÊA, L. A. (2008). Cidade Vida: curso de desenho ambiental urbano. São Paulo, Nobel.

GUIMARÃES, P. P. (2004). Configuração urbana: evolução, avaliação, planejamento e urbanização. São Paulo, ProLivros. 
KEIRSTEAD, J. e SHAH, N. (2011). Calculating minimum energy urban layouts with mathematical programming and Monte Carlo analysis techniques. Computers, Environment and Urban Systems, n. 35, pp. 368-377.

KOWALTOWSKI, D. (2011). Arquitetura escolar - o projeto do ambiente de ensino. São Paulo, Oficina de textos.

LEED, U. S. (2009). Green Building Council. LEED for Neighborhood Development. Disponível em: www. gbcbrasil.org.br/?p=leed-for-neighborhood-development. Acesso em: 10 maio 2014.

LIMA, C. de A. (2004). Multiespacialidades e a construção social do lugar-rumos para a sustentabilidade. Desenvolvimento e meio ambiente. Curitiba, UFPR, n. 9, pp. 39-56.

LIMA, R. S. (2003). Bases para uma metodologia de apoio à decisão para serviços de educação e saúde sob a ótica dos transportes. Tese de doutorado. São Carlos, Universidade de São Paulo.

MARIQUE, A.; DUJARDIN, S.; TELLER, J. e REITER S. (2013). School commuting: the relationship between energy consumption and urban form. Journal of Transport Geography, n. 26, pp. 1-11.

MONDO, J. A. S. (2002). Indicadores de desempenho e configuração especial urbana: um estudo de equipamentos escolares. Dissertação de mestrado. Porto Alegre, Universidade Federal do Rio Grande do Sul.

MORAES, F. A.; GOUDARD, B. e OLIVEIRA, R. (2008). Reflexões sobre a cidade, seus equipamentos urbanos e a influência destes na qualidade de vida da população. Revista Internacional Interdisciplinar INTHERthesis, v. 5, n. 2. Doutorado interdisciplinar em Ciências Humanas, UFSC.

MOREIRA, M. e HOLLANDA, D. (2007). A localização de escolas na visão global e integrada para um processo de planejamento de rede escolar. In: 16 CONGRESSO BRASILEIRO DE TRANSPORTE E TRÂNSITO, ASSOCIAÇÃO NACIONAL DE TRANSPORTES PÚBLICOS - ANTP. Anais.

PEREHOUSKEI, N. e BENADUCE, G. (2007). Abrangência das unidades básicas de saúde: a percepção da comunidade nos bairros Universo e Pinheiros no município de Maringá - PR. 2001 a 2005. Espaço \& Geografia, v. 10, n. 1.

RIO, V. del (1990). Introdução ao desenho urbano no processo de planejamento. São Paulo, Pini.

RONQUIM, J. e SILVA, R. (2011). Projetos arquitetônicos padrões de escolas públicas do Estado do Paraná. Synergismus scyentifica. UTFPR, Pato Branco.

SANTOS, C. N. F. (1988). A cidade como um jogo de cartas. São Paulo, Projeto Editores.

SCHAFER, K. L. (2002). Forma urbana e equipamentos comunitários como referenciais na elaboração de projetos urbanísticos. O caso de Navegantes - SC. Dissertação de mestrado. Florianópolis, Universidade Federal de Santa Catarina.

SECCHI, B. (2003). "Ciudad contemporânea y su proyecto. In: FONT, A. (org.). Planeamiento Urbanístico de la Controvérsia a la Renovación. Barcelona, Editora Diputació de Barcelona.

VASCONCELLOS, E. (2005). A cidade, o transporte e o trânsito. São Paulo, Prolivros.

WALKABLE AND LIVABLE COMMUNITIES INSTITUTE. Town Maker's Guide: Livable School. Disponível em: http://www.walklive.org/wp-content/uploads/2011/04/Livable-Schools-Poster.pdf . Acesso em: 20 nov 2014.

Texto recebido em 6/dez/2014

Texto aprovado em 5/mar/2015 